\title{
Research on the Path of Teaching Staff Construction in Independent Colleges
}

\author{
Dong Zhihan, Zhang Jing, Wang Xueru
}

Oriental College of Zhejiang University of Finance and Economics, Haining, Zhejiang, China

Received: 25 Sep 2021; Received in revised form: 20 Oct 2021; Accepted: 25 Oct 2021

C2021 The Author(s). Published by TheShillonga. This is an open access article under the CC BY license

(https://creativecommons.org/licenses/by/4.0/)

\begin{abstract}
Independent college is an important part of higher education in China, and it is also the guarantee of providing applied talents for China's economic and social development. Therefore, the construction of teaching staff in independent colleges is particularly important, and its comprehensive strength of teachers directly affects the quality of personnel training in independent colleges. Compared with public colleges, the overall faculty of independent colleges is still relatively weak, which is not conducive to the overall promotion of the school-running level of independent colleges. In order to better promote the construction of teachers in independent colleges, Promote the improvement of the school-running strength and teachers'level of independent colleges, Taking the construction of teaching staff in an independent college in Zhejiang Province as an example, On the basis of a profound analysis of the shortcomings faced by the construction of the teaching staff in this college, this paper puts forward some countermeasures to improve the construction of the teaching staff in this independent college, in order to make suggestions for the construction of the talent team in this independent college and provide case reference for the construction of the teaching staff in other independent colleges of the same type in China.
\end{abstract}

Keywords-independent college, Teaching staff, Talent construction, Case reference, Problem.

\section{INTRODUCTION}

Independent college is the product of the innovation of higher education running system in China, and it is a new running mode of popularization of higher education. The construction of teaching staff in independent colleges is the key to the quality of personnel training, and it is also the foundation for the survival and development of independent colleges [2]. The construction of teachers has always been a potential obstacle to the development of independent colleges [4]. The construction of teaching staff in independent colleges is faced with some problems, such as insufficient number of teaching staff, large mobility, unreasonable structure, lack of "double-qualified" teachers and weak scientific research ability [3]. The shortcomings in the construction of teachers have always been the key internal cause that restricts the deepening reform and connotation development of independent colleges [5]. As the first independent college established in Zhejiang Province, compared with public schools, this independent college is faced with a series of problems, such as weak teachers, weak scientific research ability, low output of high-level scientific research achievements, and insignificant achievements in discipline construction. In order to effectively promote the construction of teachers in independent colleges and enhance the overall strength of running schools and comprehensive strength of independent colleges, this paper takes an independent college in Zhejiang as an example to study the path of building highquality teachers in this independent college, in order to provide reference suggestions for the construction of teachers in the same type of independent colleges. 


\section{THE CURRENT SITUATION AND CHARACTERISTICS OF THE FACULTY OF THE COLLEGE}

The college is established by a university in Zhejiang Province. Like other independent colleges, the teaching staff has its particularity from the beginning of its establishment. Its teachers mainly come from the parent and are recruited independently, and a few teachers are part-time by off-campus teachers. There is a significant gap between the age distribution, educational background composition and professional title structure of the teaching staff of independent colleges and ordinary public undergraduate colleges, especially under the background of the transfer of independent colleges, the teaching staff of independent colleges is facing the challenge of poor stability.

(1) Young teachers are the main force of teachers

Figure 1 makes a statistical analysis of the age structure of teachers in the college in 2020. From the age distribution, the number of teachers aged 20-29 accounts for 13\%, the number of teachers aged 30-39 accounts for 45\%, the number of teachers aged 40-49 accounts for $28 \%$, and the number of teachers aged 50-60 accounts for 14\%, among which young teachers (20-39 years old) A further analysis of young teachers' work experience shows that most young teachers come to work directly after graduation, lacking in teaching experience and scientific research experience, and not having the working experience of their own professional enterprises or related institutions. At the same time, Figure 2 also makes distribution statistics on different levels of topics established by teachers of all ages during the 13th Five-Year Plan period, From the distribution structure, it can be seen that teachers aged 30-39 are the group with the largest number of projects at department level and above. Although the total number of projects is 29 more than that of teachers aged 40-49, the number of projects at provincial level and above is 9 less than that of teachers aged 40-49. It can be seen that teachers aged 30-39 are the main force of scientific research in XX Independent College and have the potential to sprint high-level scientific research achievements.

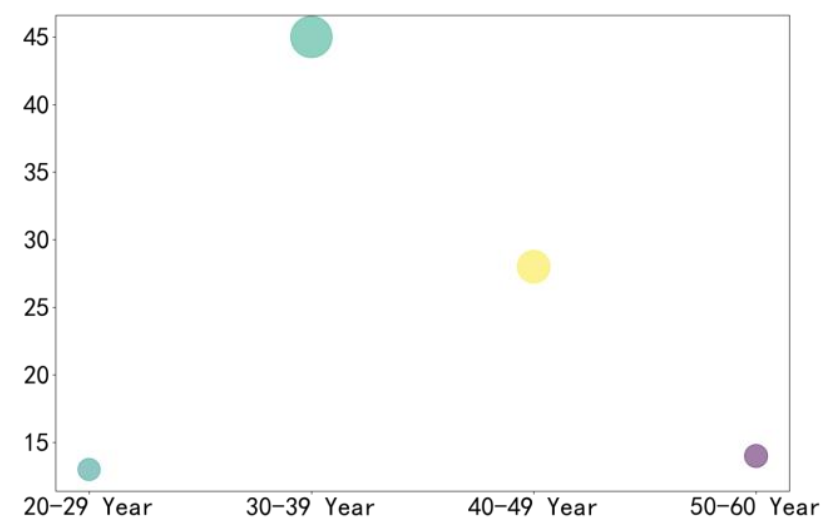

Fig. 1: Age structure of teachers in xx Independent College in 2020

(2) the academic structure of the teaching staff is not reasonable

Figure 2 makes distribution statistics on the educational background structure of teachers in XX College in 2020. From the statistical results, the number of bachelor's degree accounts for 31\%, the number of master's degree accounts for $57 \%$, and the number of doctoral degree accounts for $9 \%$. It can be seen that the educational background structure of teachers in XX College is mainly based on master's degree. Fig. 4 makes a further statistical analysis on the number of subjects with different academic qualifications and different levels in XX Independent College, Judging from the number of projects established, The number of national projects awarded by teachers with master's degree is obviously lower than that of teachers with doctoral degree, Although the total number of projects established by teachers with master's degree at departmental level and provincial level is higher than that of teachers with doctoral degree, considering the proportion of teachers with master's degree and doctoral degree in XX College, it is not difficult to know that the total number of projects established by teachers with master's degree is slightly superior to that of teachers with doctoral degree, but the projects established at provincial level and above are far less than those with doctoral degree. Generally speaking, colleges and universities should improve their own schoolrunning level and make great breakthroughs in scientific research. The proportion of doctoral teachers is higher than that of master's teachers. Obviously, the proportion of doctoral teachers in XX College needs to be improved as a whole. 


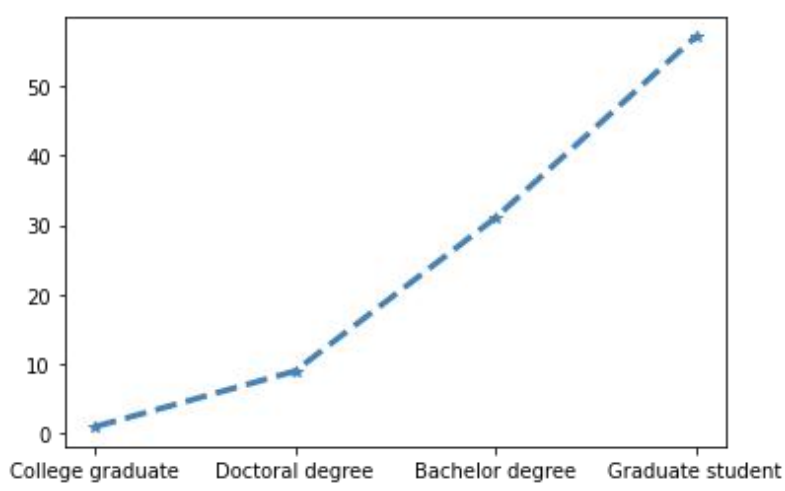

Fig.3: Teacher Education Structure of XX College, $X X$ University, Zhejiang Province in 2020

(3) the overall proportion of teachers with senior titles is small

Figure 3 analyzes the professional titles of teachers in XX College in 2020. From the distribution of professional titles, junior professional titles account for $31 \%$, intermediate professional titles account for $44 \%$, deputy senior professional titles account for $19 \%$, and positive senior professional titles account for $5 \%$. It can be seen that the number of teachers with intermediate professional titles in XX Independent College is the highest, while the number of senior professional titles is relatively small. At the same time, Figure 6 makes statistics on the projects established by teachers with different titles at different levels during the 13th Five-Year Plan period in XX College. From the project establishment results, it can be seen that teachers with intermediate titles have the largest number of departmental projects, but compared with the indicators of the number of projects established at provincial and ministerial levels and above, teachers with senior titles have significant advantages. Generally speaking, the proportion of senior professional titles in a university reflects the strength of running a university. The more senior professional titles, the stronger the comprehensive strength of the university. However, it is obvious that there is still a large gap in the proportion of senior professional titles in XX Independent College, especially the number of positive senior professional titles, which is not conducive to the development of running a school in XX College.

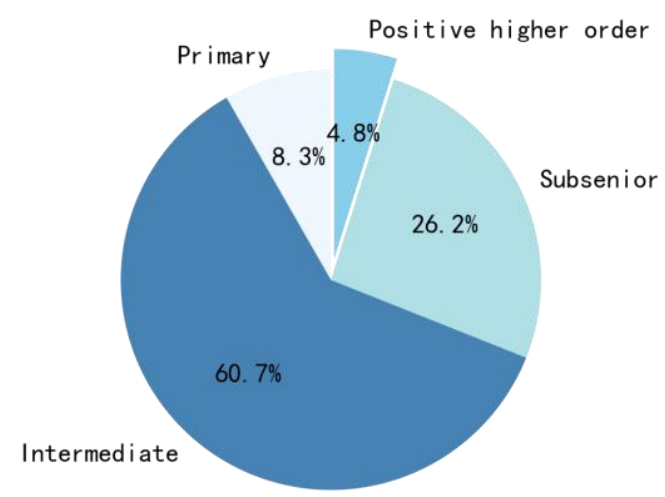

Fig.3: Distribution of teachers' titles in XX College, $X X$ University, Zhejiang Province in 2020

(4) the discipline construction lacks strong teacher support

The level of discipline development is an important embodiment of the influence of running a university. Highlevel discipline construction is backed by strong teachers, and the strength of disciplines in independent colleges reflects the strength of school teachers. During the period from 2013 to 2020, XX College carried out two rounds of applied discipline construction. Although some achievements have been made in personnel training and teacher construction, there has been no major breakthrough in the establishment of major scientific research achievements, and the scientific research achievements of members of various disciplines are not concentrated enough. Secondly, there is a certain gap between XX Independent College and independent colleges in the province, In the list of discipline construction in Zhejiang Province during the 13th Five-Year Plan published by the Education Department of Zhejiang Province in December 2016, Of the 22 independent colleges in Zhejiang Province, 23 disciplines declared by 12 independent colleges are listed as provincial construction disciplines, but the disciplines declared by $\mathrm{XX}$ Independent College are not selected. It can be seen that the overall teachers' strength behind the discipline construction of XX Independent College needs to be further strengthened and improved.

(5) The stability of the teaching staff is facing challenges

The transfer of independent colleges is the policy demand and inevitable trend of building a high-quality higher education system [6]. Of the original 22 independent 
colleges in Zhejiang Province, 5 have been converted into public colleges, 1 independent college has been converted into private colleges, and the transfer plan of the remaining 16 independent colleges is not clear yet. Since the independent college was planned to start the transfer in the second half of 2020, the transfer plan has not been clear, and the follow-up direction of running the college is unclear, which has brought confusion and anxiety to the college teachers to a certain extent. Some teachers can't work with peace of mind, while some teachers leave their jobs and move to other units. Furthermore, because XX College is a private undergraduate college, except for the teachers from the parent XX University in Zhejiang Province and the newly recruited individual excellent doctoral teachers every year, the teachers of other colleges have no career compilation. Working in colleges and universities, the identity of career establishment is an important basis for college teachers to have a sense of belonging to the unit. The vast majority of young teachers in XX College have no career establishment identity, which greatly affects the stability of the teaching staff.

\section{THE RESEARCH ON THE PATH OF TEACHING STAFF CONSTRUCTION IN XX COLLEGE}

The construction of teaching staff is an important part of the development of independent colleges, and it is also an important human resource guarantee for the development of colleges. To move towards a higher level of development, the comprehensive strength of independent colleges needs to break through the bottleneck of various talents at present, and more effective teaching staff is needed as a guarantee. The construction of teaching staff is a systematic, multifaceted and long-term project, which requires multi-party concerted efforts to promote its implementation and improve the level of teaching staff construction.

(1) Take multiple measures and do a good job in the construction of young teachers

Young teachers in independent colleges are not only the main force engaged in teaching work, but also the main force engaged in scientific research work. Improving their teaching ability and scientific research ability can not only improve the overall teaching strength and teaching level of independent colleges, but also promote the college to sprint high-level scientific research achievements. On the promotion of teaching, Independent colleges should encourage teachers to participate in various teaching skills competitions, Help young teachers to promote training, learning and teaching by competition. On this basis, independent colleges can also hire a group of teachers with excellent teaching performance to guide new teachers, and assign some new young teachers to them, so as to help young teachers gradually improve their teaching ability through the mode of passing on and helping others. In the promotion of young teachers' scientific research, independent colleges should continue to do a good job in project declaration and guidance at or above the provincial and ministerial levels, training in scientific research methods and building scientific research innovation teams, etc., and promote young teachers to produce more highlevel and high-quality scientific research results through cultivation modes such as bringing new advantages and bringing weak advantages.

(2) Go hand in hand with multiple lines to improve the overall academic qualifications of teachers

In view of the embarrassment that the distribution of teachers' academic qualifications in independent colleges is mainly based on master's degree, in order to build a rational echelon of teachers' academic qualifications, teachers' own efforts and the help of colleges can comprehensively promote the overall academic qualifications of teachers in colleges. For teachers with master's degree who are willing to upgrade their academic qualifications, independent colleges can appropriately reduce their teaching tasks, reduce teaching and scientific research assessment indicators, and give certain financial support for upgrading their academic qualifications to encourage them to improve their academic qualifications by studying for in-service doctors. Independent colleges can also strengthen cooperation with universities with the right to grant doctoral degrees at home and abroad, and promote a group of master's degree teachers to study for doctoral degrees through university-level cooperation.

(3) Multi-point support to increase the proportion of teachers with senior titles

The proportion of senior professional titles is an important window to show the overall strength of teachers in a university. It is the key for independent colleges to 
upgrade their own school-running level and increase the proportion of teachers with senior professional titles. Generally speaking, the key factor of whether a teacher can be awarded a senior professional title is how many highlevel scientific research achievements he has obtained. In order to achieve high-level scientific research results, first, teachers are required to be able to deeply grasp the frontier trends of disciplines, and second, they can closely integrate their own research with the needs of today's economic and social development. In order to help teachers create the support of these two elements, independent colleges can strengthen and deepen cooperation with well-known universities at home and abroad, and send a group of teachers to further their studies as visiting scholars, so as to better grasp the forefront trends of disciplines. Secondly, teachers are encouraged to take more posts in local enterprises and institutions, and participate in various horizontal projects undertaken by local industry colleges, so as to better grasp the key points, difficulties and hot issues of local economic and social development and better combine their research direction with regional development

(4) Multi-dimensional structure, reserve strong talents for discipline construction

The construction of a high-quality discipline system can not be separated from the support of a strong talent system. To build a discipline system with a leap in vertical comparison and a bright spot in horizontal comparison, independent colleges need to effectively reserve and consolidate the construction of talent team through the introduction and education of talents inside and outside the school. On the one hand, XX College needs to introduce high-level scientific research talents outside the school according to the needs of the construction of various disciplines, further enrich the team strength of various disciplines, and promote the output of high-quality scientific research results of various disciplines. On the other hand, internally, we should speed up the training of talents in various disciplines and vigorously enhance the scientific research ability of young teachers. At the same time, do a good job in the construction of scientific research and innovation teams, promote the formation of a good atmosphere for young teachers to gather and carry out scientific research under the guidance of scientific research backbones, adhere to the "result orientation", and build a group of high-level scientific research and innovation teams with strong scientific research and innovation ability and close scientific research cooperation among members.

(5) Take a multi-pronged approach to do a good job in stabilizing the teaching staff

At present, there are four main ways for independent colleges to be transferred: to private schools, to public schools, to terminate schools and to merge and transfer. The independent college has officially announced that "it will not merge with higher vocational colleges" and take the path of merger and conversion, so the remaining alternative conversion schemes are three paths: conversion to private, conversion to public and termination of running schools. Turning to public is the best option in the eyes of most teachers, But it also faces many problems such as the source of funds for running schools, However, no matter which transfer path the college takes, in order to better stabilize the teaching staff and push the college to the "lane" of stability, the college should link all forces to clarify the transfer direction as soon as possible, especially when formulating specific transfer plans, it should listen to the ideas and suggestions of college teachers. Furthermore, under the premise that conditions permit, young teachers should be helped to solve the problem of post establishment as much as possible, so that young teachers can have a better sense of belonging to the unit, and at the same time, they can do a good job in teaching and scientific research in their own posts with more peace of mind.

\section{CONCLUSION}

In a word, At present, there is a certain gap between the teaching level, teaching staff construction and scientific research level of independent colleges in our province and public schools. Under the background of mass enterpreneurship and innovation, independent colleges must improve the comprehensive level of teachers, increase the number of teachers with dual qualifications and dual abilities, and improve the talent introduction policy, so as to not only learn to "hematopoiesis" but also effectively "blood transfusion", thus reducing the gap with state-owned university. When developing the construction of teachers in independent colleges, We must establish a people-oriented development strategy, Especially under the background of the transfer in that year, We should improve teachers' right 
to participate and speak, attach importance to the cultivation of talent resources of teachers' echelon, build an efficient management mode of teachers, and reasonably set up reward and punishment mechanism and multi-dimensional evaluation mechanism, so as to effectively improve the teaching level and scientific research ability of teachers in independent colleges and improve the quality of running schools [7].

High-quality teachers are an important guarantee for independent colleges to train high-quality applied talents, produce high-level scientific research achievements, do a good job in the construction of various disciplines and improve the strength of running schools, and are also the capital guarantee for realizing education equity. All independent colleges in our province should carry out the construction of teaching staff according to local conditions and "one school, one policy". So as to build a team of teachers with abundant vitality, strong professional ability and good stability, promote the independent colleges in our province to become influential universities in the region and even the whole country, and continuously deliver all kinds of high-quality applied talents for the national economic and social development.

\section{REFERENCES}

[1] Que Mingkun. Analysis of the current situation and countermeasures of the transfer of independent colleges in China [J]. Educational Research. 2016, 37 (03): 64-71;

[2] Fang Huajun. Research on the Construction of Teachers in Independent Colleges of Anhui Province [J]. Journal of Anhui University of Technology (Social Science Edition). 2017, 34 (04);

[3] Wang Huiying. Reconstruction of teacher management system after the transformation of independent colleges [J]. Higher education management. 2014, 8 (06): 92-96;

[4] Wen Qiao. Research on the construction of teaching staff in private universities in China [D]. Chengdu: Sichuan Normal University, 2009;

[5] Su Ruixian, Yang Shanshan, Hu Yanru. The construction of teachers in Tianjin Independent College under the background of transfer: problems, opportunities and paths [J]. Journal of Tianjin Academy of Educational Sciences. 2021, (03): 91-96;

[6] Zhong Binglin, Jing Anlei. Analysis of the current situation of independent colleges' transfer and the sustainable development path after transfer [J]. China Higher Education Research, 2021, (04): 14-19;

[7] Hong Mei. Research on the Construction of Teachers in Private Schools [J]. Public Standard Edition, 2021, (02). 